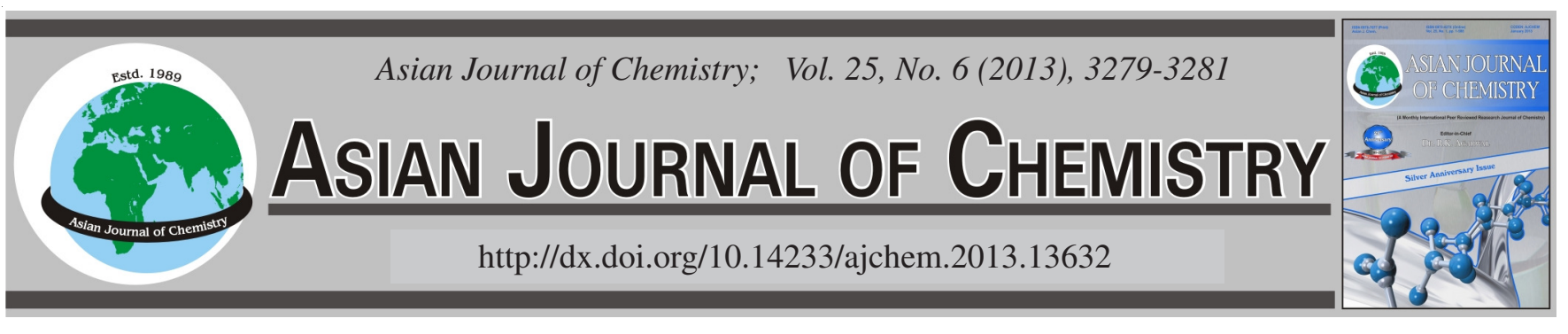

\title{
Variation of the Photon Attenuation Coefficients of Pumice Concrete in Different Chemical Media
}

\author{
I. AKKURT ${ }^{1, *}$, H. AKYILDIRIM ${ }^{1}$ and F.KARIPÇIN ${ }^{2}$
}

${ }^{1}$ Physics Department, Science Faculty, Suleyman Demirel University, Isparta, Turkey ${ }^{2}$ Chemistry Department, Science Faculty, Suleyman Demirel University, Isparta, Turkey

*Corresponding author: Fax: +90 246 2371106; Tel: +90 246 2114033; E-mail: iskender@fef.sdu.edu.tr

(Received: 20 February 2012;

Accepted: 17 December 2012)

AJC-12566

\begin{abstract}
As the radiation has started to be used in a variety of different fields after the development of technology, its shielding became one of the main research in physics. This is because of its hazardous effect on human cell. Different types of material including lead or concrete can be used to shield hazardous radiation. On the other hand the radiation shielding properties of those materials can be deformed by outer effect. The effect of chemical media on the radiation shielding properties of concrete has been investigated. The linear attenuations have been measured at 662,1773 and $1332 \mathrm{keV}$ for 6 month period. The measurement has been performed using $\gamma$-spectrometer contains a $\mathrm{NaI}(\mathrm{Tl})$ detector and $16 \mathrm{k}$ channel MCA. It was found that the chemical media decreased linear attenuation coefficients of the pumice concrete.
\end{abstract}

Key Words: Concrete, Linear attenuation coefficients, Chemical effect, Radiation.

\section{INTRODUCTION}

The increasing of the radiation using in a variety of different field makes shielding of this radiation important. Thus the radiation protection becomes important subject to be investigated in nuclear science. The $\gamma$-ray is a widely used radiation type and as it is uncharged and has no mass, it can easily penetrate into matter. The radiation shielding properties of a material is expressed with the term of linear attenuation coefficients, which is defined as the probability of a radiation interacting with a material per unit path length. The magnitude of linear attenuation coefficients depends on the incident photon energy, the atomic number and the density of the shielding materials ${ }^{1-3}$. The concrete is widely used material in building construction especially for houses.

A large number of experimental and theoretical investigations of radiation attenuation coefficients have been performed due to the importance of radiation hazards on human body. Akkurt et al. ${ }^{4}$, have measured photon attenuation coefficients of barite, marble and limra in Turkey and also measured linear attenuation coefficients of concrete containing zeolite ${ }^{5}$ and pumice ${ }^{6}$. Bashter ${ }^{7}$ made a calculation to obtain the attenuation coefficient for different types of shielding concrete. Besides those of works which are related with the determination of radiation shielding properties of the materials, the improvement of these properties has also been studied ${ }^{8}$. On the other hand, the variation of the radiation shielding properties of concrete with the chemical media has not been studied in our knowledge apart from recent work done by same author'. Rahimi et al. ${ }^{10}$, have investigated chemical corrosion on the gamma-ray attenuation properties of $\mathrm{Zr}$ and Ti containing lead silicate glasses Therefore it has been found interesting to obtain variation of photon attenuation coefficients with the chemical. In this work the concrete produced with the pumice the variation of the linear attenuation coefficients of pumice concrete has been investigated.

\section{EXPERIMENTAL}

The concrete used in this study has been obtained using pumice as an aggregate in concrete. In Table-1 the properties of pumice and cement have been tabulated. The linear attenuation coefficients $(\mu)$ were measured at the photon energies of 662, 1173 and $1332 \mathrm{MeV}$ obtained from ${ }^{137} \mathrm{Cs}$ and ${ }^{60} \mathrm{Co} \gamma$-ray sources, respectively. The $\gamma$-rays are measured with the $\gamma$ spectrometer contains $\mathrm{NaI}(\mathrm{Tl})$ connected to $16 \mathrm{k}$ channels multi-channel-anayser (MCA) with Genie $2000^{11}$ for data acquisition and analysis. If $\mathrm{N}$ and $\mathrm{N}_{0}$ are the measured count rates in detector, respectively with and without the absorber of thickness $x(\mathrm{~cm})$, the linear attenuation coefficients $(\mu)$ can be extracted by the standard equation:

$$
\mathrm{N}=\mathrm{N}_{0} \mathrm{e}^{-\mu \mathrm{x}}
$$


TABLE-1

CHEMICAL COMPOSITION OF THE CEMENT AND PUMICE

\begin{tabular}{ccc}
\hline Chemical composition & CEM I 42,5 N & Pumice \\
\hline $\mathrm{CaO}$ & 61.00 & 12.12 \\
$\mathrm{MgO}$ & 3.56 & 1.06 \\
$\mathrm{NaO}$ & - & 0.40 \\
$\mathrm{~K}_{2} \mathrm{O}$ & 0.11 & 3.60 \\
$\mathrm{Fe}_{2} \mathrm{O}_{3}$ & 3.81 & 0.80 \\
$\mathrm{SiO}_{2}$ & 22.56 & 56.00 \\
$\mathrm{Al}_{2} \mathrm{O}_{3}$ & 7.11 & 12.10 \\
$\mathrm{SO}_{2}$ & 2.70 & - \\
$\mathrm{SiO}_{2}$ & - & 12.70 \\
$\mathrm{H}_{2} \mathrm{O}$ & - & 9.30
\end{tabular}

Plotting $\operatorname{In}\left(\mathrm{N}_{0} / \mathrm{N}\right)$ versus $\mathrm{x}$ would give straight line and $\mathrm{m}$ can be obtained from the value of the slope. In Fig. 1 the $\gamma$-ray spectrum has been displayed obtained for ${ }^{60} \mathrm{Co}$ source with and without concrete sample.

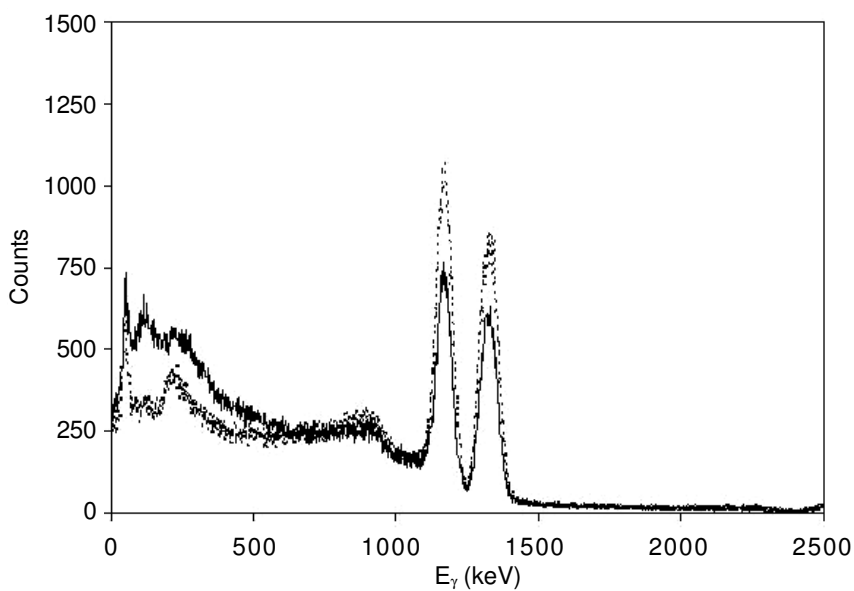

Fig. 1. Photon energy spectrum with and without concrete between detector and ${ }^{60} \mathrm{Co}$ radioactive source

\section{RESULTS AND DISCUSSION}

In order to investigate the chemical effect on the linear attenuation coefficients, the concrete contains pumice has been left in two different types of chemical media for 6 month period. The chemical media were $\mathrm{NaOH}$ and $\mathrm{Na}_{2} \mathrm{SO}_{4}$ solutions where the linear attenuation coefficients have been measured in each month for 6 months. The results have been displayed in Fig. 2 for $\mathrm{NaOH}$ and in Fig. 3 for $\mathrm{Na}_{2} \mathrm{SO}_{4}$. It can be seen from these figures that the linear attenuation coefficients have decreased with the increasing leaving time of concrete in the chemical media. This could be the result of deformation in the concrete structure with the chemical effect. In order to see the effect of chemical types the linear attenuation coefficients have been displayed in Fig. 4. It can be seen from this figure that the linear attenuation coefficients have decreased sharper in $\mathrm{NaOH}$ medium than $\mathrm{Na}_{2} \mathrm{SO}_{4}$. The transmission rate for 662 , 1173 and $1332 \mathrm{keV}$ as a function of concrete thickness has been placed in Fig. 5 for $\mathrm{NaOH}$ and in Fig. 6 for $\mathrm{Na}_{2} \mathrm{SO}_{4}$. It can also be seen from those figures that the chemical media effects concrete structure and the stopped thickness of the concrete. Comparing 662, 1173 and $1332 \mathrm{keV}$ photon energies (Fig. 5 and Fig. 6) it can be seen that the larger concrete is needed for higher energy photons.

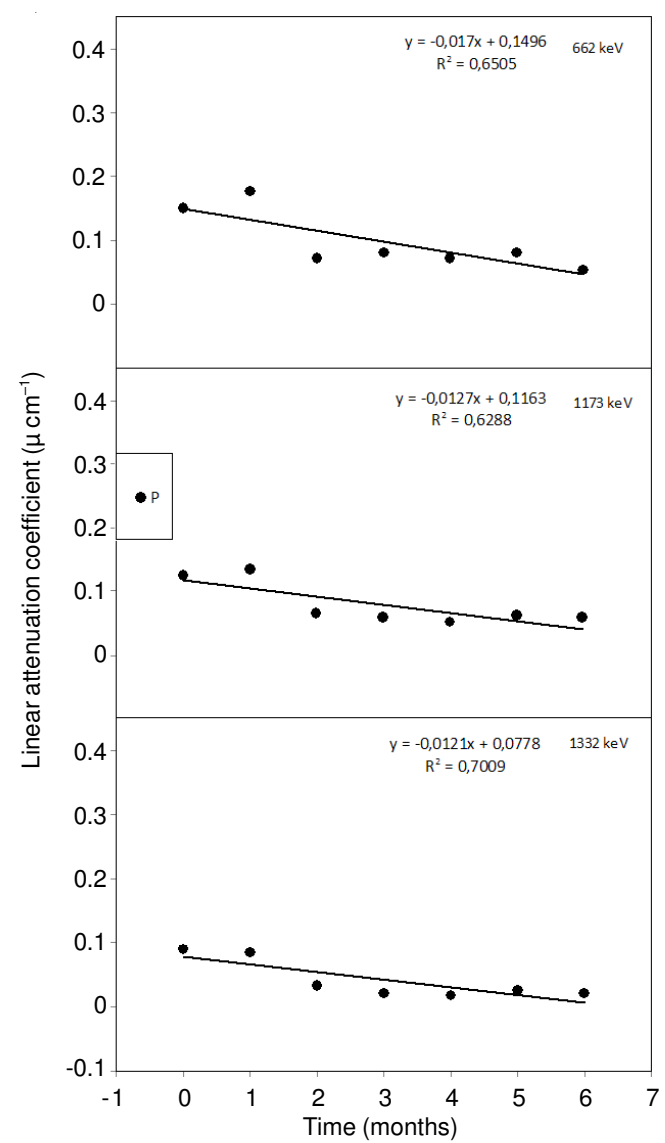

Fig. 2. Variation of the linear attenuation coefficients with the time for 662, 1773 and $1332 \mathrm{keV}$ energy photons in $\mathrm{NaOH}$ medium

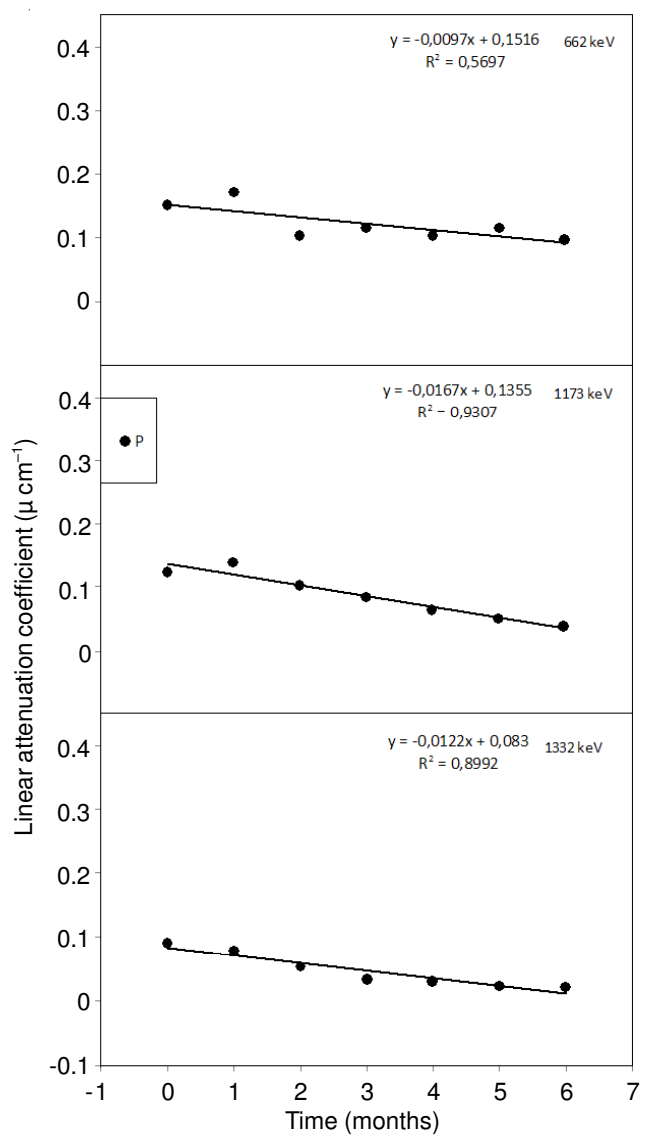

Fig. 3. Variation of the linear attenuation coefficients with the time for 662,1773 and $1332 \mathrm{keV}$ energy photons in $\mathrm{Na}_{2} \mathrm{SO}_{4}$ medium 


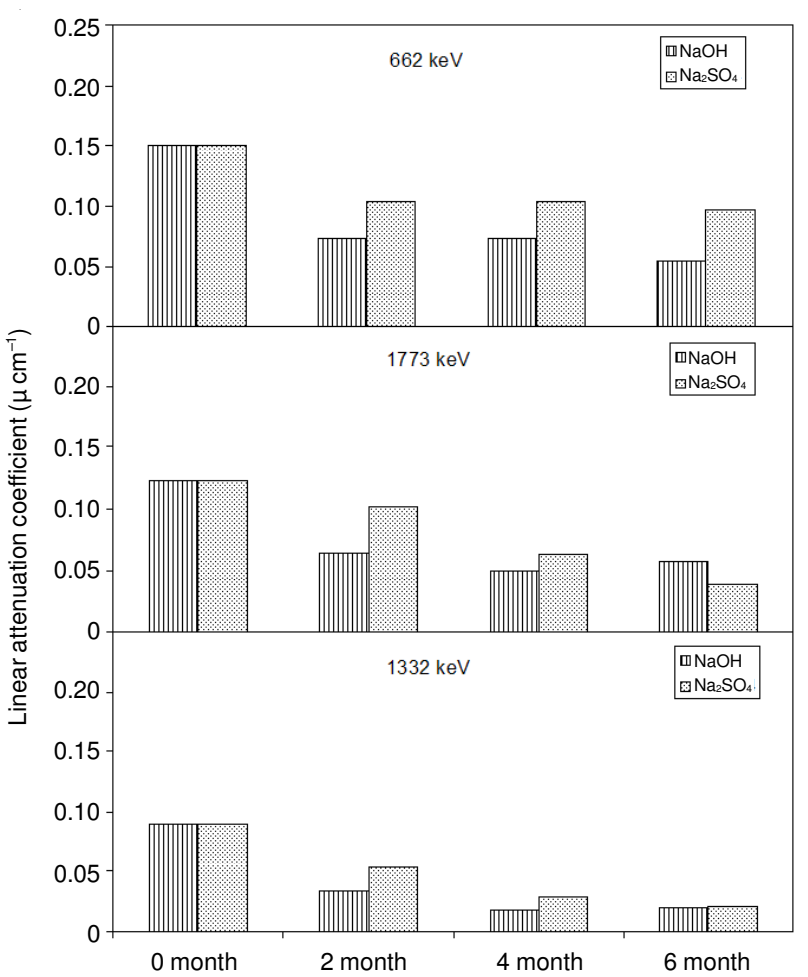

Fig. 4. Variation of the linear attenuation coefficients with the different chemical media obtained at 662, 1773 and $1332 \mathrm{keV}$ energy

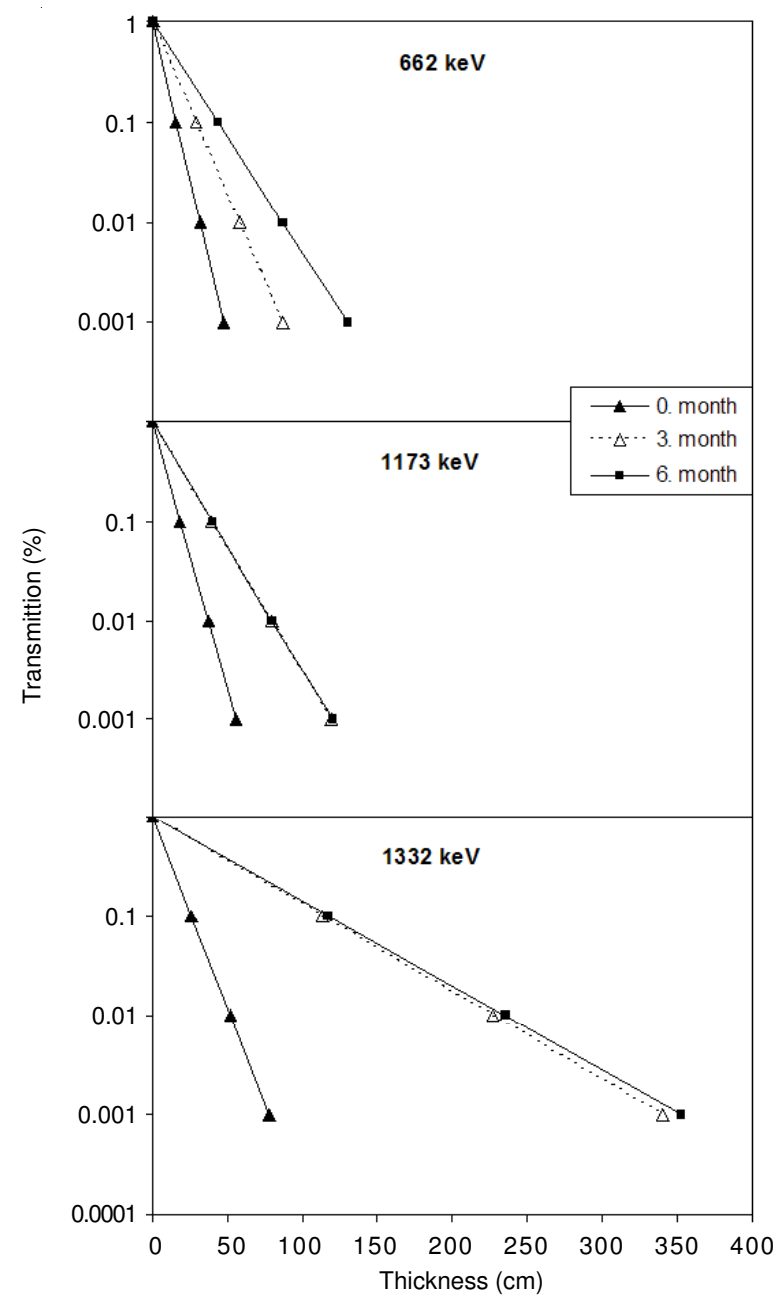

Fig. 5. Transmission rate of $\gamma$-rays at different energies for various month chemical effect in $\mathrm{NaOH}$ medium

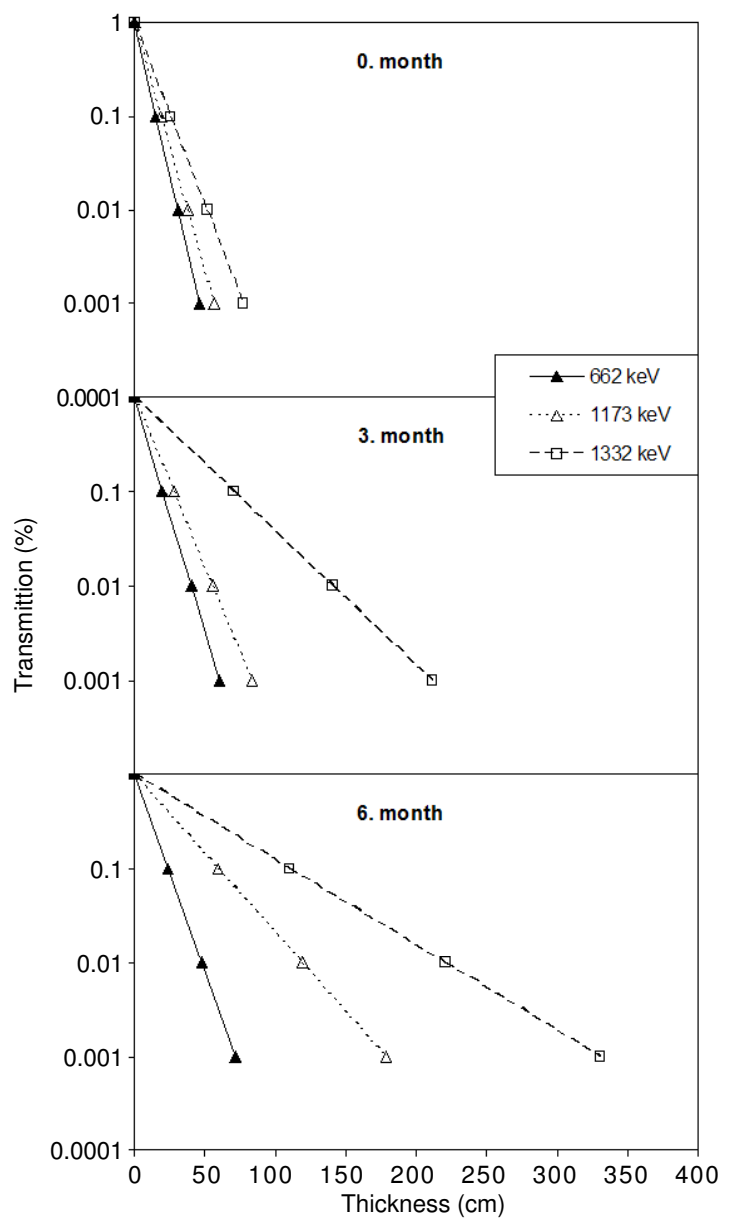

Fig. 6. Tansmission rate of $\gamma$-rays at different energies for 662,1173 and $1332 \mathrm{keV}$ photon energies in $\mathrm{Na}_{2} \mathrm{SO}_{4}$ medium

It can be concluded from this work that the radiation shielding properties of concrete containing pumice has been effected by the chemical media.

\section{ACKNOWLEDGEMENTS}

This work has been supported by TUBITAK under project No: 106M127

\section{REFERENCES}

1. I. Akkurt, B. Mavi, A. Akkurt, C. Basyigit, S. Kilincarslan and H.A. Yalim, J. Quant. Spect. Rad. Trans., 94, 379 (2005).

2. I. Akkurt, C. Basyigit, S. Kilincarslan and B. Mavi, Prog. Nucl. Energy, 52, 620 (2010).

3. J. Woods, Computational Methods in Reactor Shielding, Pergamon Press, New York (1982).

4. I. Akkurt, C. Basyigit and S. Kilincarslan, Ann. Nucl. Energy, 31, 577 (2004).

5. I. Akkurt, H. Akyildirim, B. Mavi, C. Basyigit and S. Kilincarslan, Rad. Measur., 45, 827 (2010).

6. I. Akkurt and H. Akyildirim, Nucl. Eng. Design, 252, 163 (2012).

7. I.I. Bashter, Ann. Nucl. Energy, 24, 1389 (1997).

8. A. Iskender, Ç. Adnan, A. Hakan and M. Betül, Z. Naturforsch., 63a, 445 (2008)

9. I. Akkurt, H. Akyildirim, F. Karipcin and B. Mavi, J. Saudi Chem. Soc., 16, 199 (2012).

10. R.A. Rahimi, G. Raisali, S.K. Sadrnezhaad and A. Alipour, J. Nucl. Mater, 385, 527 (2009).

11. Genie2000(3.0) 2004, Operation Manual, Canberra Industries 